\title{
Microsurgical resection of ambient cistern arteriovenous malformation
}

\author{
Omar Choudhri, MD, and Michael T. Lawton, MD \\ Department of Neurosurgery, University of California, San Francisco, California
}

The middle tentorial incisural space, located lateral to the midbrain and medial to the temporal lobe, contains the ambient cistern through which courses the third, fourth, and fifth cranial nerves, posterior cerebral artery (PCA), superior cerebellar artery, and the choroidal arteries. Arteriovenous malformations (AVMs) in this compartment are supplied by the thalamogeniculate and posterior temporal branches of the PCA, and drain into tributaries of the basal vein of Rosenthal. We present a case of an AVM in this middle tentorial incisural space that persisted after embolization and radiosurgery, and was microsurgically resected through a subtemporal approach. This case demonstrates the anatomy of the middle incisural space and technical aspects in microsurgical resection of these rare AVMs.

The video can be found here: https://youtu.be/V-dIWh8ys3E.

KEYWORDS arteriovenous malformation; subtemporal craniotomy; ambient cistern; microsurgery; tentorial incisura; video 